\title{
A for Ambulate
}

\section{Authors: Faisal B Chaudhry, ${ }^{A}$ Jayne Brown, ${ }^{B}$ Amar Bhat ${ }^{B}$ and Neil Stewart ${ }^{C}$}

\author{
Aims \\ To reduce admissions and create beds while providing top quality \\ service.
}

\section{Methods}

We transformed an already existing, nurse-led day unit and clinic area into an ambulatory unit. We converted the sitting hall into a patient area, by fitting partition curtains and placing two trolleys and three couches, accommodating five patients at one time. The old clinic room was converted into isolation. Three rooms at the back of this area were converted into a doctor's office, store room and base for hospital at home team, working in liaison with ambulatory unit.

The referral system was through a dedicated phone line, email, paper and e-messaging through patient record software. To cover working hours from 8 to 6 , a shift rota was made for doctors and nurses in three shifts. We acquired four dedicated ultrasound and two computed tomography slots per day and two echocardiography slots per week.

To assess performance, the number of admissions through medical take over 8 months from October 2016 to May 2017 was compared with data from the same months in the previous year (October 2015 to May 2016).

\section{Results}

A total of 4,049 patients were seen on medical takes from October 2015 to May 2016. After establishing the ambulatory unit, from October 2016 to May 2017, this number reduced to 3,423 . Considering the expected annual rise in admissions of $2.8 \%$ across the NHS, this shows a reduction of $17.75 \%$, ie 739 patients presenting to medical take. This reduction in admissions allowed us to successfully close a 35 bed ward. As all cause mean length of stay in England is 5 days and average cost of a 1 day stay in hospital is $€ 400$, on average one hospital admission costs around $£ 2,000$. Hence over 8 months, Rowan ambulatory unit by avoiding 739 admissions has saved $€ 1.49$ million, averaging $£ 185,000$ per month. Total cost of running this unit, pay and nonpay expenditure combined, over these 8 months was $£ 176,439$, so

Authors: ${ }^{\mathrm{A}}$ Acute General Medicine, Oxford University Hospital

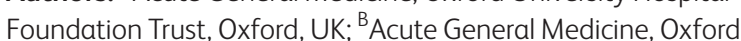
University Hospital NHS Foundation Trust, Banbury, UK; ' Ceratology, Oxford University Hospital Foundation Trust, Oxford, UK net saved $£ 1,301,561$ (average of $£ 162,695$ per month). This does not take into account any reduction in length of stay by supporting early discharge.

\section{Conclusion}

The NHS deals with over one million patients in 36 hours. Hospital admissions per annum have increased by $28 \%$ over one decade (16.252 million in 2015/16 compared with 12.679 million in 2005/06). Ambulatory units are an efficient way of dealing with this increased pressure on the NHS, helping with bed management and meeting budget targets.

\section{Conflict of interest statement}

None declared. 